This is a post-print version of: Wyatt, M. (2011). Teachers researching their own practice. ELT Journal 65 (4), 417-425.

http://eltj.oxfordjournals.org/content/early/2010/12/27/elt.ccq074.abstract

\title{
Teachers researching their own practice
}

\author{
Mark Wyatt \\ University of Portsmouth
}

Unfortunately, despite encouragement from the literature, it seems that many teachers only rarely engage in action research. For this to change, further support may be required from in-service language teacher education courses that include an action research component. In this paper, I report on one such course: an in-service BA TESOL run by a British university for the local Ministry of Education in a Middle Eastern country. Using qualitative case study methodology, I identify the achievements of four teachers who engaged in action research as part of their studies on this course and draw on their own words as they reflect on the benefits of researching their own practice. Conclusions focus on elements of the programme that may have helped them.

\section{$\underline{\text { Introduction }}$}

There are various benefits that student-teachers can accrue from researching their own practice, as they focus their intellects, academic knowledge and personal experience on conducting classroom-based research (Steinberg \& Kincheloe 1998). Unfortunately, however, many teachers rarely engage in research unless encouraged to do so by teacher education (Borg 2009a).

To help teachers become research-active, Borg (2009b) suggests, teacher education courses can be organized and structured in certain ways. For example, they can include awareness-raising activities, and opportunities for the participating teachers to put ideas into practice, set their own goals and evaluate their own progress. Supportive mentoring and feedback, and opportunities to meet recycled input may also help. In addition, with sufficient space and time, participating teachers may more easily develop their ideas. Thus, the inclusion, in course design, of extensive action research projects that encourage deep personal engagement can be beneficial, as can institutional support, in the form of reduced workloads.

Successful outcomes of engaging in research might include the development of research skills, increased awareness of the teaching / learning process, renewed enthusiasm for teaching, greater collaboration with colleagues (Atay 2008), enhanced self-efficacy (Henson 2001) and continuing commitment to professional development following the teacher education intervention (Kirkwood \& Christie 2006). Teachers may thus be empowered, pedagogically, 
cognitively and politically (Steinberg \& Kincheloe op.cit.), to become more active in supporting learning. However, notwithstanding the work of Atay (op.cit.), writing in a Turkish context, little of this supporting evidence comes from the field of ELT (Borg 2009a).

In this article, I report on how four teachers of English on an in-service BA TESOL in the Middle East benefited from conducting action research in their teaching contexts. Drawing on qualitative data, I report on their achievements through action research and their reflections on the process.

\section{The context}

Teacher research, which can be defined as: 'systematic, rigorous enquiry by teachers into their own professional contexts' (Borg op.cit.: 377), was a key component of the teacher education programme I am investigating (a threeyear BA TESOL run by the University of Leeds for the Ministry of Education in the Sultanate of Oman). Teachers studied for the degree part-time, attending lectures and seminars one day per week during the school term at a regional training centre; they taught on the other days. There were also intensive study blocks held exclusively in Oman (apart from one six-week block in the UK) during the height of summer and winter; these were staffed by lecturers from Leeds and regional tutors based in Oman. I was one of the latter, working with a group of 35 teachers throughout the course, running a regional training centre, lecturing, providing tutorial support, and visiting the teachers in their schools once a semester to observe lessons and provide feedback on teaching practice that was not assessed.

The research strand ran through the BA programme. There were modules focused explicitly on research and others that encouraged the development of research skills more indirectly. The assignment for the very first module, for example, required teachers to plan a communicative activity, teach and then evaluate it. This involved them in developing criteria, observing while they taught, assessing learning outcomes and reporting on these. For another module in the first year (2003), teachers were required to keep a reflective journal that focused on language acquisition and learning issues, and many planned and then evaluated modest interventions with their learners.

Research had a higher profile in years two and three. In the third semester (February-May 2004), teachers were asked to identify a topic they might like to explore through action research, prior to more formal input provided by a Researching TESOL module in the second year summer school: This module defined action research with the help of Burns (1999), as research they could do in their own school contexts that would involve them actively in evaluating learning, planning interventions and reflecting, with a view to improving their own practices. In the fourth semester (September-December 2004), the teachers were required to produce a detailed research proposal, on 
which they received written feedback (in February 2005). In the fifth semester, with time allocated for this, they conducted their research with tutorial support. They then made preliminary presentations of their findings during the summer school (July 2005). In the final semester, they produced 6,000word dissertations to submit at the end of the year. There was thus a steady focus on research throughout the final three semesters of the course, supported by lectures and seminars (see Atkins, Lamb \& Wedell, 2009, for more information about the BA programme).

This programme took place at a time of curriculum renewal; some teachers were using a new more learner-centred curriculum with smaller classes in brand-new schools, while others were working with a more traditional curriculum being phased out, which they were permitted to adapt.

\section{$\underline{\text { Research Methods }}$}

My research questions are as follows:

1. What did the teachers achieve through their action research?

2. How do they feel they benefited from it?

The research I am reporting on here was part of a multi-case study, as Stake (2006) describes these. This followed five teachers' development over three years and focused on practical knowledge and self-efficacy growth in relation to themes, such as using communicative tasks, designing materials and developing reading skills, that emerged in the individual cases. These themes were related to the teachers' professional concerns and became their action research topics (Wyatt 2008). My focus in this paper is on this action research component of the course, as the teachers worked towards their dissertations; the over-arching concepts of the original study, practical knowledge and selfefficacy, are not the focus here.

Another difference between this paper and the original study is that I draw on data relating to four not five of the participating teachers, all of whom were volunteers who signed informed consent forms promising anonymity and the right to withdraw at any time. These teachers were selected for the original study according to various criteria suggested by Stake (op. cit.), including balance, variety and the opportunities they provided for me to learn from them. For this paper, a further criterion, determining the selection of four from five, was willingness to explore practice with a view to changing it; this seems crucial if teachers are to benefit from action research. The fifth teacher (not included here) wanted to help his learners overcome difficulties in reading, but, unfortunately, without doing things very differently in the classroom; this limited his uptake of new ideas (I will discuss his case and the complex issues involved in a separate paper). My focus in the present paper is on the positive achievements and benefits that can accrue from engaging in action research, if teachers are open to this form of enquiry. 
In addressing research questions, I draw on various qualitative methods. I conducted semi-structured interviews (Kvale \& Brinkmann 2008), observations, in which my own role was as a 'non-participant observer' (Cohen, Manion \& Morrison 2007), and analysed both the teachers' written work and feedback on this produced by markers in the UK.

These methods supported my analysis as follows: Observations, which allowed me to see how teachers used action research, were always followed by interviews, which provided opportunities to elicit reflections and explore cognitions in relation to this use. By analysing their assignments, which were their written accounts of planning and engaging in action research, I gained further insights into the teachers' cognitions and reported behaviour; markers' feedback supplied independent evaluations of their action research projects I could compare with my own. I used all four of these methods in addressing my first research question; interview data helped me address the second.

Throughout the three-year research period, I observed each teacher 5-6 times and interviewed them on 7-8 occasions. For this paper, I have drawn largely on data gathered in the last 15 months of the course, when I observed each teacher 3 times (for 35-40 minutes on each occasion). These observations were followed by 45-50 minute interviews. Assignments I analysed included research proposals and dissertations. Data referred to are coded as follows (after Borg 1998):

\begin{tabular}{|l|l|l|} 
Teacher's pseudonym & Source of data & Number \\
\hdashline Mariyam - M & Assignment - A & $1-8$ \\
Rashid - R & Feedback - F & \\
Sarah - S & Interview - I & \\
Waleed - W & Observation - O &
\end{tabular}

So, SA.5 is Sarah's fifth assignment, SO.4 her fourth observation, SI.6 her sixth interview, SF.7 feedback on her seventh assignment.

Results are organized around research questions.

\section{$\underline{\text { Results }}$}

\section{What did the teachers achieve through their action research?}

To address this question, I first describe each teacher's research in turn, before summarizing their achievements.

Sarah

Sarah was concerned that her Grade 9 students did not get enough meaningful speaking practice and designed communicative tasks to 
supplement each unit of the course book, which she described as "based on drilling and repetition" (SA.5). Communicative tasks, she argued in her proposal, could motivate her learners and encourage them to express their feelings fluently in English in new situations. For her research, Sarah would evaluate the effectiveness of communicative tasks she designed with the help of audio recordings of lessons and observation notes (SA.5). The lesson I observed in this cycle appeared well-structured, learner-centred and highly motivating (SO.4). She reflected on it insightfully (SI.6). In her dissertation, Sarah analysed transcripts of learners' speech, recorded while they were speaking communicatively. Features of this provided evidence that the use of communicative tasks supported acquisition processes (SA.7). Feedback described her dissertation as: "very well-written and very interesting" (SF.7). Sarah resolved to share her findings with other teachers (SI.7), and subsequently disseminated her work more widely.

\section{Rashid}

Rashid, working with the new curriculum, was using group work for the first time (RI.1). He was concerned about low-achieving Grade 5 students (unfortunately labelled as 'weak' by the school administration) not benefiting enough from activities that involved them in working in groups. He decided to focus on four such learners in one of his classes. He would teach a short series of lessons containing a variety of activities, each observed by two teachers as well as himself. In these lessons, he would vary the classroom organization; grouping the learners according to mixed abilities, allowing them to form friendship groups, giving the low achievers particular responsibilities (RA.2). I observed one of these lessons, in which Rashid reorganized the learners at the start, set up the group work efficiently and demonstrated sensitivity to the needs of the learners in various ways; e.g. by being particularly attentive, discretely encouraging other students to involve the low achievers (RO.5). Reflecting afterwards, he demonstrated keen observational and analytical skills (RI.6). In his dissertation, which was praised for its "original and interesting work" (RF.4), he drew sensible conclusions, based on evidence, including implications for his own teaching (RA.4). Rashid shared his experiences with others, using evidence from this research to inform an in-house workshop he conducted in his school (RA.3) (RI.7).

\section{Waleed}

Waleed was concerned about the creative use of materials to support learning. Working with a curriculum being phased out, he had noticed early in his career that learners appeared to find the course materials repetitive and he tried to make these more exciting, e.g. by colouring in plain flashcards, introducing more varied activities and using supplementary materials, including those he designed, such as activity cards and worksheets, and those he found, such as realia and pupils' craftwork created for other subjects (WI.5). His adaptation of materials increased, he reported, during the first year of the 
BA programme, during which time he felt both his understanding of young learners and his analytical skills developed (WI.8). At the same time, Waleed was conscious that other English teachers in the school, who would subsequently join a later cohort of the BA programme, appeared to neglect the materials they were provided with; these were left lying around, sometimes "thrown" in the corner of the staff room, unused. For his action research, he would observe colleagues' classes, interview them and try to help (WA.4). He subsequently found that both these teachers' use of and awareness of how to use materials were relatively limited, and he designed a short series of lessons he invited them to observe, through which he demonstrated how materials could be used creatively (WA.6). The lesson in this sequence I observed was highly original, well-sequenced and distinguished by a creative use of varied materials that appeared to support motivation and learning in the class (WO.4). The observers reported gaining new ideas they said they would try to use (WI.7). Waleed's "very interesting" dissertation reporting on this intervention was praised for the appropriateness of his research design and his "very good understanding of the issues" (WF.6). In the following semester, he led two workshops for the teachers in his school, one on conducting action research and one on using materials creatively (WI.8).

\section{Mariyam}

As Senior English Teacher of her school, Mariyam had responsibilities that included helping other teachers (several of whom would subsequently join a later cohort of the BA programme) develop as reflective practitioners. Mariyam was conscious that her own capacity to reflect in English on her teaching had developed; she reported that her understanding of concepts and her analytical skills, as well as her language ability, had grown. Accordingly, she now felt far more comfortable reflecting critically in post-lesson discussions with her supervisor (who elicited much more than traditional inspectors had in the past) (MI.4). However, the other English teachers in her school still found it very difficult to talk about their work in such settings (MA.1), and, indeed, complained to Mariyam about the challenges (MI.4). Mariyam resolved both to help them reflect more critically on their teaching and develop her own ability to stimulate reflection through questioning. For her action research, she would video lessons she observed with the teachers' permission and then use these videos during the post-lesson discussions, stimulating recall using 'why' questions. (I observed one of these lessons with her and listened to an audio recording of the post-lesson discussion.) She would then organize further input through workshops and peer observations, before observing the teachers again (MA.1). Mariyam reported positive outcomes from the research. Teachers overcame initial nerves and lack of familiarity with the research method to speak more freely about their work (MI.6, MA.3). The marker noted that she had learned a great deal about stimulating reflection and had done "an impressive amount of work" (MF.3). Mariyam subsequently disseminated her research more widely. 


\section{Summary}

It is evident that all four teachers achieved much through engaging in carefully constructed and well executed action research. Firstly, they were able to address important concerns that related to the contexts they worked in. Sarah was concerned about learners gaining insufficient speaking practice, Rashid about low achievers not gaining enough support in group work activities, Waleed about teachers making insufficient use of materials, Mariyam about teachers being unable to reflect on their lessons.

Their interventions addressed these concerns, and so, secondly, they engaged in behaviour that helped others. In their dissertations, they all reported evidence of this: of Grade 9 learners' greater engagement in speaking activities and production of more authentic speech, of low achievers' fuller engagement in certain types of group work; of teachers they worked with gaining ideas about materials they could use or gaining confidence in reflecting on their teaching.

Thirdly, they all disseminated their research. This was possible through inhouse workshops, regional conferences known locally as forums where teachers could discuss research, in-house Ministry of Education publications that synthesized findings and a series of edited dissertations, showcasing some of the best work from the various cohorts of the BA Programme; e.g. Borg (2009c).

\section{How do the teachers feel they benefited from engaging in action research?}

To address this question, I draw on interview data, which I present in relation to themes that emerged.

The teachers were conscious of their achievements in helping others Mariyam, for example, told me: "I helped the teachers think more about reflection, everyday reflection on their teaching, and to think more about learning" (MI.7), for which they were grateful. One thanked Mariyam for helping her feel more self-confident about analysing her work:

She was only looking at her lessons generally, but now she can divide the lesson into steps and stages and think about them and relate each aim to each other, but she needs more help and more support in future, also (MI.6).

Similarly, Rashid reported:

I've got a deep understanding of organizing groups and identifying low achievers and where to put them because I don't consider them as obstacles or difficult cases in my class. It's easy now, with the use of group work, to help them and to improve their levels... They're still low achievers but they can improve (RI.7). 
The teachers developed research skills

Waleed reported that, from conducting research for his dissertation he had learned: "many things...how to collect data, how to observe my students or myself and the other teachers, how to evaluate the materials, how to analyse them, how to interpret, how to make suggestions for the next cycle" (WI.7). "I learned that you have to put some criteria for observation. After that you can analyse very easily" (WI.8).

Similarly, Rashid reported:

I learned where to focus on the problems of the pupils and the effects, like participation, motivation, and I learned how to investigate these problems and how to find out and how to notice, actually, from the observation while I'm teaching, to be a researcher and a teacher at the same time (RI.6).

Sarah highlighted how her planning skills had developed, as well as her ability to assess learning outcomes: "You cannot do this unless you are a good observer and you know your goals and your aims" (SI.7).

Running through these comments from Waleed, Rashid and Sarah is their self-awareness of their developing practical skills in doing research. These skills (in planning, setting criteria, observing, assessing, evaluating) are crucial for teachers conducting classroom-based action research. Mariyam also talked enthusiastically about a method she used, stimulating recall with the video (MI.7) (an established practice in ELT research worldwide but novel in this particular context). These experiences were empowering. "The main thing", Rashid told me, "is that now I've got the skills to do other research" (RI.7).

The teachers found it rewarding

Mariyam told me: "It was my choice [of dissertation topic] and I loved to work on it very much and try to make it as successful as I could" (MI.7). Similarly, Sarah reported: "Really, it is wonderful if all the time you're doing something for your students, observing them and seeing what their difficulties are and trying to solve [these difficulties] through the research" (SI.7).

\section{Summary}

To summarize, the teachers highlighted various benefits of engaging in action research. These included their own awareness of their achievements in helping others through doing the research, their sense of their developing research skills and the rewarding, highly motivating nature of the research experience. As the statements quoted above also suggest, the teachers seemed to become more efficacious in different aspects of their work and more autonomous. 
These findings thus support those of other studies that have investigated the benefits teachers accrue from engaging in action research (Kirkwood \& Christie op.cit.; Atay op.cit.). In the case of these four teachers, the successful experience of engaging in research, together with the self-awareness of how it had helped them, empowered them to support change processes in their teaching contexts, as Steinberg \& Kincheloe (op.cit.) argue action research is able to do. Learners and fellow teachers were beneficiaries.

\section{Conclusion}

This small-scale study (focusing on just four teachers in a Middle Eastern context) thus provides evidence that incorporating action research into teacher education programmes can be beneficial. Features of this particular BA TESOL that may have helped were as follows:

- The programme was run on a part-time basis in the teachers' local context. This allowed the participating teachers to combine teaching and learning, so that they could more easily relate theory to practice and draw on practical experience when they approached theory.

- Mentoring was a feature of the programme. A regional tutor visited the teachers in their schools to observe and discuss lessons.

- Practical experience of conducting classroom-based research was gained at a very early stage in the three-year programme (for the first assignment).

- Input on conducting action research was provided at an appropriate stage of the course and then recycled through the following semesters.

- Time was provided for teachers to work on their research projects.

- An appropriate timeframe that allowed for reading around the topic, developing a research proposal, collecting, analysing and presenting data, and writing up, was put in place.

- The teachers were allowed autonomy in identifying and developing their action research focus, though guidance through tutorials was provided.

These features of the programme might explain the outcomes, with regard to these four teachers, in terms of successful action research experiences, the development of research skills and greater motivation, self-awareness, selfefficacy and autonomy. However, there is no suggestion that all teachers presented with similar support would develop in the same way - indeed, a fifth teacher who was part of the same multi-case study (Wyatt 2008) did not. Individual differences are clearly crucial. In addition, there is no suggestion that such growth can always be sustained once the support provided by the teacher education programme is withdrawn upon course completion. Unfortunately, as Borg (2009a) reminds us, contextual challenges can limit teachers' ability to continue to research. Indeed, one of the teachers in this 
study, Rashid, subsequently found it harder to put insights gained from action research into practice due to new school policies (Wyatt in press).

Nevertheless, the qualitative data presented here has highlighted the growth in teachers that can occur. Furthermore, this paper does suggest that introducing an action research element to in-service language teacher education courses may be highly beneficial, for at least some of the teachers, if it is planned for and supported carefully.

\section{References}

Atay, D. 2008. Teacher research for professional development. ELT Journal $62 / 2 ; 139-147$.

Atkins, J., Lamb, M. and M. Wedell (eds.). 2009. International collaboration for educational change: The Oman BA project. Muscat: Ministry of Education, Sultanate of Oman.

Borg, S. 1998. Teachers' pedagogical systems and grammar teaching: A qualitative study. TESOL Quarterly 31/1; 9-38.

Borg, S. 2009a. English language teachers' conceptions of research. Applied Linguistics 30/3; 358-388.

Borg, S. (ed.). 2009b. Researching English language teaching and teacher development in Oman. Muscat: Ministry of Education, Sultanate of Oman.

Borg, S. (ed.). 2009c. Understanding English language teaching and learning in Oman. Muscat: Ministry of Education, Sultanate of Oman.

Burns, A. 1999. Collaborative action research for English language teachers. Cambridge: CUP.

Cohen, L., Manion, L. and K. Morrison. 2007. Research methods in education (Sixth edition). London: RoutledgeFalmer.

Henson, R.K. 2001. The effects of participation in teacher research on teacher efficacy. Teaching and Teacher Education 17/7; 819-836.

Kirkwood, M. and D. Christie. 2006. The role of teacher research in continuing professional development. British Journal of Educational Studies $54 / 4 ; 429-448$.

Kvale, S. and S. Brinkmann. 2008. Interviews: Learning the craft of qualitative research interviewing (Second edition). Thousand Oaks: Sage. 
Stake, R.E. 2006. Multiple case study research analysis. New York: The Guilford Press.

Steinberg, S.R. and J.L. Kincheloe. 1998. Students as researchers: creating classrooms that matter. London: Falmer Press.

Wyatt, M. 2008. Growth in practical knowledge and teachers' self-efficacy during an inservice BA (TESOL) Programme. Unpublished PhD thesis, School of Education: University of Leeds, UK.

Wyatt, M. 2010. An English teacher's developing self-efficacy beliefs in using groupwork. System 38/4, 603-613.

Please cite as:

Wyatt, M. (2011). Teachers researching their own practice. ELT Journal 65 (4), 417-425.

http://eltj.oxfordjournals.org/content/early/2010/12/27/elt.ccq074.abstract 